\title{
Why Bangladeshi Patients Prefer Outbound Medical Travel? An Analytical Study
}

\author{
Dhanonjoy Kumar ${ }^{* 1}$ \\ Sraboni Bagchi ${ }^{2}$ \\ Shimul Ray ${ }^{3}$ \\ Islamic University, Kushtia, Bangladesh ${ }^{1 \& 3}$ \\ Pabna University of Science and Technology, Pabna, Bangladesh ${ }^{2}$
}

\begin{abstract}
Bangladesh is a densely populated country within the world and the health sector of this country is relatively poor; they're being enhanced day by day. The study focuses on deliberate outbound medical travel from Bangladesh and sees the important factors that influence preferring foreign medical treatment of Bangladeshi patients. In this study, nonprobability convenience sampling and structured questionnaires are used for collecting the data. Some essential statistical tools are used to prove the hypotheses. It absolutely found that individuals chose to foreign countries from Bangladesh for cardiovascular, dental, infertility/IVF, and cancer treatments and folk were identified because of the foremost important medical treatments that persuade the patients to choose a special country. The availability of physicians and better service quality, sufficient medical facilities and services, treatment cost, and hygienic, safety, security, and attractive tourist medical places are the most important factors driving individuals to seek outbound medical services. Keywords: Medical Travel, Health Disease, Service Quality, Treatment Cost, Bangladesh
\end{abstract}

Corresponding author: Dhanonjoy Kumar; E-mail: dhanonjoykumarsaha@gmail.com DOI: https://doi.org/10.37227/ITHJ-2021-05-1088

\section{Introduction}

According to the World Health Organization (WHO), chronic diseases are the largest cause of death in worldwide. In 2016 ischemic heart disease alone took the lives of 9.43 million people, for cardiovascular diseases 17.9 million deaths worldwide each year. All types of cancer, lung disorders, and diabetes are among the primary chronic diseases that cause the most fatalities each year. Lung cancer alone claimed the lives of almost 1.7 million people in 2018, while liver cancer claimed the lives of nearly 782 thousand people (Elflein, 2020). In South Asia, cardiovascular, respiratory, and neonatal conditions, which include birth asphyxia and trauma, neonatal sepsis and infections, and preterm birth complications are the top global causes of death, in order of total number of lives lost. Infectious and parasitic diseases, as well as maternal, perinatal, and nutritional disorders, fall into three categories: communicable, non-communicable (chronic), and injuries. Infections that can be prevented are a leading cause of mortality and disability. Infections such as pneumonia, diarrhea, and measles were responsible for more than two-thirds of the estimated 3.7 million children deaths of South Asia in 2000. 
India is the the world's second-largest AIDS and HIV population, and tuberculosis and chronic hepatitis continue to threaten the lives of millions of people. Around 63 percent of all infectious disease-related deaths in the region occur in children under the age of five (Zaidi, et al. 2015). The healthcare sector is one of the most demanding in any developing country with a large population. It necessitates increased spending in terms of GDP and the availability and fair access to medical treatment and services for the local people. Bangladesh's public healthcare system is overcrowded, with a shortage of funding, medical experience, and technology, and there are few great private institutions that cater to local requirements. Medical travel is becoming a preferred social phenomenon for people globally. Health means individuals' bodily, psychological and social well-being, which isn't simply inadequate to the lack of illnesses (Aydin \& Karamehmet, 2017). It's asserted that tourism isn't limited to leisure trips; it establishes journeys started for additional causes like a commercial, health, and other purposes (McKinsey, 2008). Broadly it's the act of traveling to urge treatment. Medical tourism has three forms that are outbound medical tourism, inbound medical tourism, and domestic/ intra-bound medical tourism (Deloitte, 2008). Maswood (2017) stated that the patients of Bangladesh flight to bordering states like India, Malaysia, Singapore, and Thailand for improved treatment. Rahman (2019) found that Bengali favored Kolkata, with its shopping and other entertainment services score high on the must-do list.

Alom (2019) revealed that Malaysia is progressively turning into a high alternative medical tourist destination for Bangladeshi people. Due to a lack of trust in local physicians and a weak diagnostic system, around 700,000 Bangladeshis travel overseas for medical care each year and spend US\$ 3.5 billion. People mostly travel to India, Singapore, Thailand, and Malaysia for the treatment of different severe ailments. Bangladeshi medical tourists go to India in the largest numbers, with an estimated 425,000 patients seeking treatment in various South Asian countries each year. The public health experts of Bangladesh have forecasted that outbound medical tourism will grow if local healthcare institutions fail to win the trust and confidence of patients (The Apparel News, 2018). The Financial Express, a renowned newspaper of Bangladesh, reported in October 2019 that approximately US $\$ 4.0$ billion is spent on medical expenses outside of the country. Bangladesh Investment Development Authority found that about 128,000 Bangladeshis spent more than US $\$ 2.0$ billion in the year 2012 seeking treatment in India, Thailand, and Singapore. In 2017, the number of Bangladeshis traveling to India on medical visas jumped to over 221,000 .

In reality, an increasing number of Bangladeshis are traveling abroad in search of better medical care (Zahid, 2019). In Bangladesh government hospitals, private hospitals and clinics are providing healthcare services for the inhabitants. Bangladesh continues to lag behind in providing health care services to both the poor and the wealthy. India and Thailand, have made significant progress in recent years in terms of doctor competence and experience, innovation of healthcare technologies, and high-quality hospitals and health management organizations. Technological partnership with technologically advanced hospitals is required and the implementation of health management organizations in established Asian countries and advanced Western nations (Mahmood, 2012). This study observes the abstract and practical features related to outbound medical travel and the likelihood of integrating this idea into the developmental strategies for Bangladesh. So, this paper blends this prior study on health travels and detects some important requisites that are to be measured through the event of coming tourist policies. 


\section{Objectives of the Study}

The study formulated the following focal objectives:

- To investigate why Bangladesh patients prefer outbound medical travel from Bangladesh.

- To identify the important factors affecting the outbound medical travel decision.

\section{Overview of World Medical Industry}

Healthcare industries are the largest and fastest-growing industries in the world. Healthcare consuming more than $10 \%$ of the gross domestic product (GDP) in most developed countries can significantly affect a country's economy (KFF, 2006). The healthcare industry is a collection of industries that provide goods and services to treat patients with curative, preventative, rehabilitative, and palliative care. It encompasses the creation and commercialization of goods and services that aid in maintaining and restoring health. The modern healthcare industry is made up of three main branches: services, products, and finance. It is split into a variety of sectors and classifications, and it relies on interdisciplinary teams of trained professionals and paraprofessionals to address the health needs of people and populations (ETA, 2012).

A growing number of nations compete for patients in the medical tourism industry by offering a wide range of medical, surgical, and dental treatments. These take place in their contemporary facilities, which feature cutting-edge technology and inviting lodgings and tourism destinations may be found on the global map of medical tourism. Now, medical services in India are very economical, with rates as low as $10 \%$ lower than those in the United States. Several established European countries, including Belgium, Canada, Germany, and Italy, are attracting international patients with sophisticated modern treatment that emphasizes patient service and pleasure (Mestrovic, 2021). Medical tourism encompasses both outbound travel to some other country for medical treatment and crossborder trading in healthcare services among neighboring developing nations. Medical tourism is an instance of India and Bangladesh's mutual trading in medical care services. In the $21^{\text {st }}$ century, the huge number of medical tourists traveling overseas for medical treatment, as well as the foreign exchange income gained by the host nation, define the success of cross-border medical services commerce (Ali and Medhekar, 2016).

\section{Overview of Bangladesh Medical Industry}

Bangladesh is a highly populated developing country in the world. Many people live in poverty, and they are subjected to natural calamities such as floods every year during the monsoon season. Although primary healthcare provision has improved, many people continue to face issues with access, affordability, and the quality of medical facilities and treatment due to overcrowding, non-availability of treatment and medical facilities, a scarcity of skilled and experienced health professionals, and rising corruption (Ali and Medhekar, 2016). Bangladesh has made significant progress in the health sector in the 49 years since independence. The development of health infrastructure has been remarkable. Modern facilities are being added to medical institutions, medical universities, private medical colleges, private clinics, private hospitals, district hospitals, rural health centers, and community clinics to grow their numbers and improve their quality.

The DGHS has 739 hospitals, all of which contribute significantly to Bangladesh's healthcare. Government secondary and tertiary hospitals, Upazila and union hospitals, registered private hospitals and clinics, and registered private diagnostic centers are all 
committed to delivering healthcare to the people. The number of hospital beds in both public and private hospitals is increasing. The number of seats in healthcare teaching and training facilities has expanded in recent years, as has the number of teaching and training institutions (DGHS 2020). The following table is summarizing the present scenario of the health sector:

Table 1: Scenario of Health Sector in Bangladesh

\begin{tabular}{|l|l|r|}
\hline Sl. & Particulars & Number \\
\hline 1. & Total number of Government facilities & 2,258 \\
\hline 2. & Total number of registered private hospitals & 5,321 \\
\hline 3. & Total number of registered private diagnostics centers & 9,529 \\
\hline 4. & No. of hospital beds under the DGHS & 54,660 \\
\hline 5. & No. of hospital beds in private hospitals registered by the DGHS & 91,537 \\
\hline 6. & $\begin{array}{l}\text { Total number of facilities run by DGHS, including registered } \\
\text { private hospitals }\end{array}$ & 7,579 \\
\hline 7. & Personnel currently working under DGHS of MOHFW & 78,619 \\
\hline 8. & Number of doctor currently working under DGHS of MOHFW & 25,594 \\
\hline 9. & No. of registered physicians: MBBS & $1,01,538$ \\
\hline 10. & No. of registered physicians: BDS & 9,875 \\
\hline 11. & No. of medical technologists & 5,208 \\
\hline 12. & Population per registered physician & 1,487 \\
\hline
\end{tabular}

Source: DGHS- Health Bulletin, (2019)

Lack of proper medical equipment and facilities, life-saving medicines, diagnostic services, experienced specialist physicians, and trained nurses plague public hospitals. Bangladeshi government contributes substantial sums of money to health care in its budget every year, but it is insufficient to fulfill the local demand. The shortage of highly skilled and experienced healthcare personnel and expensive medical, diagnostic, and surgical expenses are major concerns for the private sector. In Bangladesh, there is also the widespread public opinion of the poor quality of healthcare services given by public and private health institutions. Rahman's (2000) concluded that the quality of healthcare services, health costs and the non-availability of certain medications are the important reasons for higher cross-border medical travel from Bangladesh.

\section{Outbound Medical Travel}

The World Health Organization (WHO) defines medical tourism often known as health tourism or health travel. People who travel overseas for medical treatment are referred to as medical tourists. Previously, this term was used to describe people who traveled from lessdeveloped countries to major medical centers in developed countries for treatment that was not available at home (Horowitz, et al. 2007). The 2008 Deloitte report on medical Tourism provides a good overview of inbound medical tourism. Patients from other nations travel to the United States for medical treatment, which is known as inbound medical tourism. Patients from the United States travel to other nations to receive medical care, which is known as outbound medical tourism (Medical Tourism Magazine, 2019). So, outbound medical travel is a situation where patients travel to other countries for receiving medical services. 


\section{Relationship Between Outbound Medical Travel and Different Factors}

Outbound medical travel is influenced by a variety of push and pull factors. High healthcare costs at home, being underinsured or uninsured, the treatment being unavailable for ethical or regulatory grounds, and extensive surgery waiting lists are all push factors. The pull factors are the host country's atmosphere, the destination's attraction, the cost of desired treatment, overseas-educated medical personnel, JCI accreditation, and the medical tourism facilities' and services' equivalent or superior quality (Collins et al. 2019). The people of Bangladesh prefer outbound medical tourism because of expert physician support, service quality, medical service packages, treatment cost, and the health environment. Expert physician support involves courteous, friendly, and highly qualified doctors and nurses do not show authoritarian doctor's gaze, which makes patients more comfortable to interact and may attract potential patients. Service quality with cutting-edge medical facilities, service adequacy, proper medical practice, efficient medical staff; medical service packages that may include special offers and discounts, insurance plan, hotel, travel, and tourism costs; affordable treatment cost that may include transportation cost and medical care costs; and health environment including hygiene environment, tourism attractions, travel safety, accommodations, branded hospital, accredited hospitals, and familiarity with the native language and English language and culture influence Bangladeshi patients for outbound medical travel.

\section{Literature Review}

Khaled (2017) revealed that a rail connection between Khulna to Kolkata and Kolkata to Khulna in Bangladesh and a replacement public utility between Dhaka and Kolkata were inaugurated earlier within April 2017. The increase of Bangladesh within the Indian travel market has been relatively rapid. Bangladesh has unseated the USA because of the very best number of foreign tourists since 2016, most of the medical tourism. Expertise in medical support is an essential factor for cross-border medical tourism. Chakraborty (2017) found that Bangladeshi citizens received about 58,000 medical visas during the year 20152016. More than 165,000 of the 460,000 inbound patients to Indian hospitals were from the neighboring country. They purchased $\$ 0.34$ billion worth of services revealed by the Directorate-General of Commercial Intelligence and Statistics. Bangladesh has surpassed the United States as the source of the most international tourists since 2016, owing primarily to medical tourism. Rahman (2019) found that the Indian High Commission processed around 3000 visas per day with particular walk-in services for those seeking medical care on an average.

It follows naturally that the more Bengali favored Kolkata, with its shopping and other entertainment facilities, will score high on the must-do list. Physicians are more than ready to provide prescriptions for visits, making the medical visa procedure go more smoothly. There are also unrestricted monthly visits by these physicians under the umbrella of so-called clinics for consultation and further treatment in India. Sun (2018) suggested that health treatment cost, excellence of care, hospital accreditation, and doctor experience inspire patients' medical facility choice. Ajmera et al. (2015) explained that the international sections of Indian hospitals ensure quality services for international patients. Maung and Walsh (2014) revealed that some progressive private sector hospitals with trained doctors and quality service heights bear a good meaning for inviting overseas patients in Thailand. Aniza et al. (2009) studied that Malaysia is creating a mark in the medical travel business. Malaysia now enjoys medical and practical expertise, the best quality substructure, economic and political stability, and beautiful fantasy tourist land. 
Lajevardi (2016) perceived that the quality of medical operations and services helps patients select target destinations. Service quality is an important factor that requires a cross-border medical tourism decision.

Tontus and Nebioglu (2018) concentrated on advanced countries' people stalking for substitute healthcare facilities and travel to emerging countries for profitable treatment. Mokoena and Haarhoff (2016) indicated choosing a health travel target destination depends on medical facilities uniformity, the superiority of facilities, and appreciation. Musa et al. (2012) suggested outstanding medical facilities, cost of services, subsidiary services, spiritual issues, and ethnic similarity are key motivational issues for making travel decisions. Medical service packages help the patients to get medical service. The people from the least developed states travel to highly advanced states to get good medical support and services (George, 2009). Afroz and Hasanuzzaman (2012) stated that medical service packages with entertainment trips help patients decide on medical travel. Kumar and Raj (2015) revealed that India has an advantage of very cheap medical costs, and it positions second among other countries in the world. The tour and hotel packages offered by the hospitals in India are one more advantage for medical treatment. Borg et al. (2017) revealed that high treatment costs of countries are USA \& Japan to average cost countries are Germany \& Singapore to low-cost countries are India \& Poland.

Cost bears a great significance for making healthy traveling decisions. Haque et al. (2018) stated that cost, service quality, and service charges are the motivation tools for considering health tourism. Medical facilities in Bangladesh are terribly poor. Kunwar and Srivastava (2019) examined cross-cultural conduct and intercultural communication between the congregations and guests. Bochaton (2015) revealed that shopping, travel, and individual visits are the important reasons for patients visited in Thailand. Leng (2007) found that for Indonesian patients, medical travel Malaysia is the eminent destination. Collins et al. (2019) investigated that there are four key elements that might impact on American medical tourists for choosing medical tourism in the USA. These elements include the attractiveness of a tourism location, medical tourism expenses, and health tourism facilities and services. They also stated that, in order to attract international medical tourists, the United States should provide patients with higher-quality medical and tourism facilities than the five most popular tourism destinations: India, China, Thailand, Mexico, and Turkey.

Ali and Medhekar (2018) stated, in comparison to Bangladesh, Physicians in Thailand were foreign-trained, compassionate, trustworthy, honest, and forthright with patients, and had the competence to offer clinical outcomes for a variety of illnesses. Thailand offers a shorter surgical waiting time, modern medical facilities, and good healthcare service, leading to an increase in outbound medical travel from Bangladesh. Islam and Biswas (2014) argued that Bangladesh's health system is highly reliant on the government or the public sector for funding, policymaking, and service delivery systems. Despite the fact that the health system faces several significant barriers, it appears to be given little importance in terms of national resource allocation. Mahmood (2012) identified Bangladesh's healthcare systems facing a severe problem in terms of health care delivery. Bangladeshi healthcare services are affected by absenteeism of medical experts, corruption, a scarcity of doctors/nurses, inefficiency, and mismanagement.

Ali (2012) observed high costs, improper treatment, poor services, and long wait times at home, as well as new technology and skills in healthcare destination countries, as well as lower transportation costs and Online marketing, have all played a key role in the advancement of medical tourism from Bangladesh to other countries. Hasan and Hassan 
(2013) found the healthcare industry is expanding at a faster rate. Patients, particularly in wealthy nations, are attempting to lower their healthcare costs by seeking better hospitals in other countries, resulting in a new idea known as health tourism or medical tourism. Health tourism is becoming a lucrative business in certain Asian nations, such as China, India, Thailand, and Singapore. They hoped that Bangladesh had the potential to become an undiscovered health tourism destination.

\section{Hypotheses}

Ho1: There has no significant affiliation between outbound medical travel and expert physician support.

Ho2: There has no significant affiliation between outbound medical travel and service quality.

Ho3: There has no significant affiliation between outbound medical travel and medical service packages.

Ho4: There has no significant affiliation between outbound medical travel and treatment cost.

Ho5: There has no significant affiliation between outbound medical travel and the health environment.

\section{Methodology}

To conduct the research, both quantitative and qualitative research approaches were used. Among the varied methods of obtaining primary data, researchers conducted the subsequent methods: (i) Interview method; (ii) Observation method, and (iii) Library work method. Secondary documents are inexpensive and more rapidly accessible than primary documents. It has been collected from related books, circulated information of newspapers, journals, seminar papers, publications from national and international research institutions. A questionnaire was designed to collect the data. The ultimate questionnaire was circulated to the selected respondents using social media, precisely, messenger and WhatsApp. Contributors were invited to answer investigations to two key sections, section-I was seven (7) demographic variables, and section-II was 14 (fourteen) independent variables and one dependent variable. Simple random sampling was used for data collection. Data was collected for this research by creating a self-administered survey and therefore, the questionnaire has been distributed with the assistance of online social media platforms. Total 221 questionnaires were usable for data analysis. Five-point Likert scales were used here, that's ranking 1 (strongly disagree) from 5 (strongly agree). The existing study Cronbach's alpha value is 0.715 , which indicates suitable consistency and reliability. SPSS and AMOS were used for processing the data and hypothesis testing. 
Data Analysis and Interpretation

Table 1: The patients' socio-demographic profile

\begin{tabular}{|c|c|c|c|}
\hline \multicolumn{2}{|l|}{ Particulars } & Respondents & Percentage \\
\hline \multirow{5}{*}{ Age } & 00 Years to 15 Years & 2 & 0.9 \\
\hline & 16 Years to 30 Years & 48 & 21.7 \\
\hline & 31 Years to 45 Years & 115 & 52.0 \\
\hline & 46 Years to 60 Years & 37 & 16.7 \\
\hline & 61 Years to above & 19 & 8.6 \\
\hline \multirow{2}{*}{ Gender } & Female & 48 & 21.7 \\
\hline & Male & 173 & 78.3 \\
\hline \multirow{7}{*}{ Occupation } & Teaching & 50 & 22.6 \\
\hline & Business & 28 & 12.7 \\
\hline & Farmer & 13 & 5.9 \\
\hline & Housewife & 28 & 12.7 \\
\hline & Service & 66 & 29.9 \\
\hline & Students & 30 & 13.6 \\
\hline & Others & 6 & 2.7 \\
\hline \multirow{6}{*}{ Monthly Income } & No Income & 32 & 14.5 \\
\hline & 01 to 15000 Taka & 36 & 16.3 \\
\hline & 15001 to 30000 Taka & 45 & 20.4 \\
\hline & 30001 to 45000 Taka & 21 & 9.5 \\
\hline & 45001 to 60000 Taka & 32 & 14.5 \\
\hline & 60001 Taka to above & 55 & 24.9 \\
\hline \multirow{5}{*}{$\begin{array}{l}\text { Preferable Country for } \\
\text { medical travel }\end{array}$} & India & 179 & 81.0 \\
\hline & Singapore & 18 & 8.1 \\
\hline & Thailand & 5 & 2.3 \\
\hline & Japan & 4 & 1.8 \\
\hline & Others & 15 & 6.8 \\
\hline \multirow{7}{*}{$\begin{array}{l}\text { Source of information } \\
\text { about available medical } \\
\text { aids of a particular } \\
\text { country }\end{array}$} & Friends & 36 & 16.3 \\
\hline & Internet & 30 & 13.6 \\
\hline & Referrals/ Relatives & 75 & 33.9 \\
\hline & Doctors & 22 & 10.0 \\
\hline & Medical tourism agency & 13 & 5.9 \\
\hline & Family members & 29 & 13.1 \\
\hline & Others & 16 & 7.2 \\
\hline
\end{tabular}

\section{Source: Personal Survey}

From Table 1, we see that the highest $52 \%$ of the respondents were in the age group of between 31 years to 45 years. $78.3 \%$ of them were male. In terms of their profession, a maximum of $29.9 \%$ were service holders. $81 \%$ of respondents preferred India for medical travel, and a maximum of $33.9 \%$ of patients collect outbound medical tourism information from their relatives. 
Figure 1: Prefer to Take Outbound Medical Services

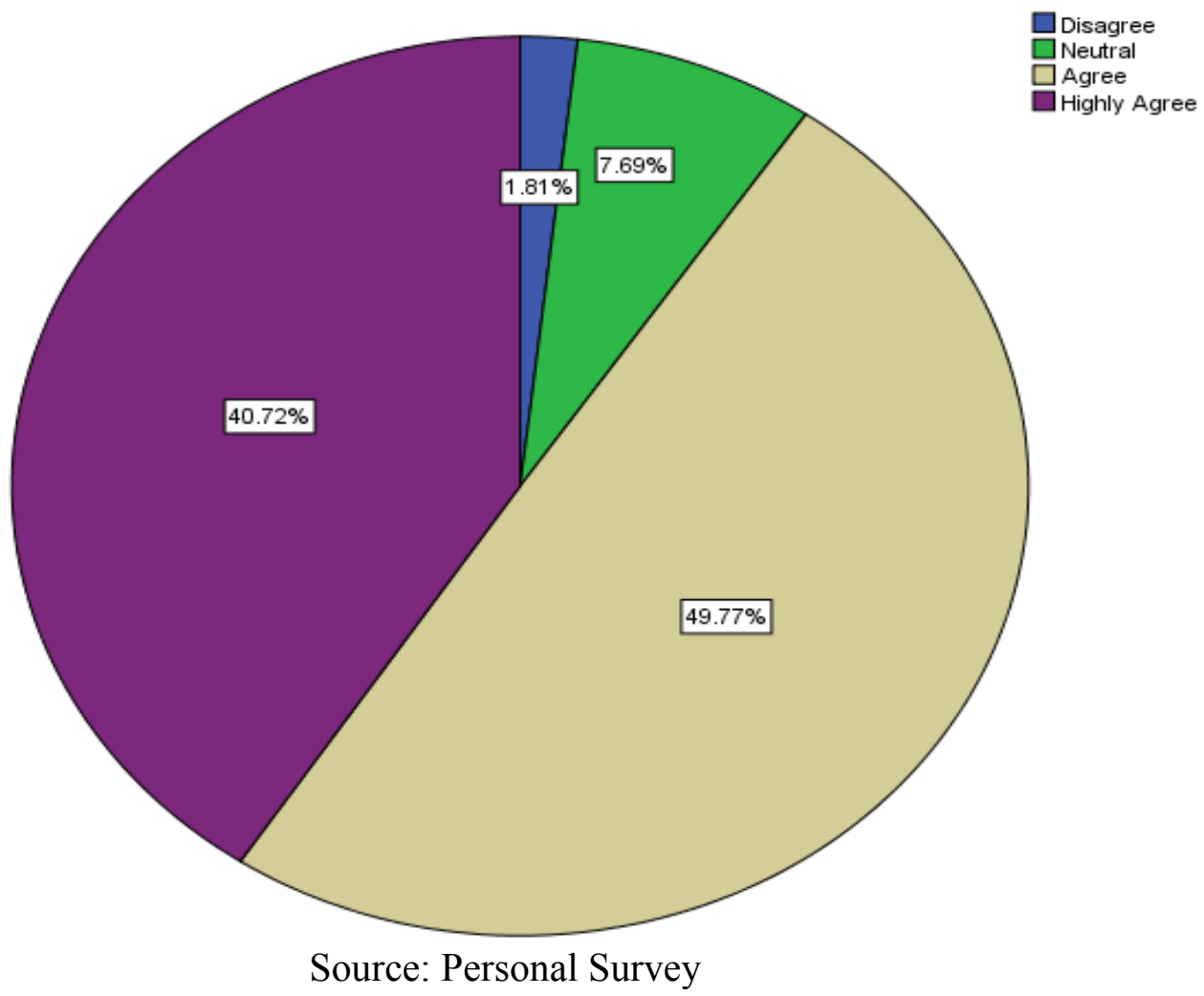

The above figure represents the respondents' comments that prefer to take foreign medical services. The figure shows that the majority of the respondents, $49.77 \%$ are agreed, $40.72 \%$ respondents are highly agreed, $7.69 \%$ respondents are neutral, and $1.81 \%$ respondents are disagreed for preferring to take foreign medical services.

Table 2: KMO and Bartlett's Test

\begin{tabular}{|l|l|c|}
\hline $\begin{array}{l}\text { Kaiser-Meyer-Olkin Measure of Sampling } \\
\text { Adequacy. }\end{array}$ & .739 \\
\hline Approx. Chi-Square & 604.374 \\
\hline $\begin{array}{l}\text { Bartlett's Test of } \\
\text { Sphericity }\end{array}$ & df & 105 \\
\cline { 2 - 4 } & Sig. & 0.000 \\
\hline
\end{tabular}

Source: Calculated by SPSS 20 software

The KMO was 0.739 . The significant value of Bartlett's test at $\mathrm{p}<0.001$ indicates that the current data set was suitable for data reduction techniques in SPSS (factor analysis) and proved sufficient correlations between the variables. 
Table 3: The Results of Factor Analysis

\begin{tabular}{|c|c|c|c|c|c|}
\hline Particulars & $\begin{array}{c}\text { Expert } \\
\text { physician } \\
\text { support }\end{array}$ & $\begin{array}{l}\text { Service } \\
\text { quality }\end{array}$ & $\begin{array}{c}\text { Medical } \\
\text { service } \\
\text { Packages }\end{array}$ & $\begin{array}{l}\text { Treatment } \\
\text { Cost }\end{array}$ & $\begin{array}{c}\text { Health } \\
\text { environment }\end{array}$ \\
\hline $\begin{array}{l}\text { Adequate Cost of } \\
\text { Treatment }\end{array}$ & & & & .703 & \\
\hline $\begin{array}{ll}\text { Proper } & \text { Medical } \\
\text { Practice } & \\
\end{array}$ & & .512 & & & \\
\hline $\begin{array}{ll}\text { Offered better } \\
\text { Service }\end{array}$ & .756 & & & & \\
\hline $\begin{array}{ll}\text { Efficient } & \text { Medical } \\
\text { Staff } & \\
\end{array}$ & & .525 & & & \\
\hline $\begin{array}{ll}\text { Sufficient } & \text { Medical } \\
\text { Facilities } & \\
\end{array}$ & & .742 & & & \\
\hline Service Quality & .582 & & & & \\
\hline Service Adequacy & & .697 & & & \\
\hline $\begin{array}{l}\text { Medical Aids and } \\
\text { Tourism }\end{array}$ & & & & & .541 \\
\hline Insurance Plan & & & .697 & & \\
\hline $\begin{array}{l}\text { Special Offers and } \\
\text { Discount }\end{array}$ & & & .797 & & \\
\hline Transportation Cost & & & & .733 & \\
\hline Safety and Security & & & & & .556 \\
\hline $\begin{array}{l}\text { Hygienic } \\
\text { Environment }\end{array}$ & & & & & .671 \\
\hline $\begin{array}{l}\text { Prefer Abroad for } \\
\text { Medical Treatment }\end{array}$ & .656 & & & & \\
\hline $\begin{array}{l}\text { Availability of } \\
\text { Expert Doctors }\end{array}$ & 629 & & & & \\
\hline
\end{tabular}

Source: Calculated by SPSS 20 Software

From the above table, it has been found that variables like offered better service, availability of expert doctors, preference aboard for medical treatment and service quality respectively have formed the first factor named 'Expert physician support'. Four variables like sufficient medical facilities, service adequacy, proper medical practice, and efficient medical staff have been created together with the second factor named 'Service quality. On the other hand, special offers and discounts and insurance plans have been created together with the third factor 'Service packages'. At the same time, Transportation Cost and Adequate Cost of Treatment respectively have been created together with the fourth factor named 'Treatment cost'. Again, hygienic environment, safety and security and medical aids and tourism have created the fifth factor named 'Health environment'. Again, all the variables had an acceptable communalities score which is more than 0.5 . The factors and variables that are explained above helped for clarifying as quality indicators for preferring to take outbound medical travels. This result demonstrates that these fifteen quality indicators can provide positive information for preferring to take foreign medical services. 


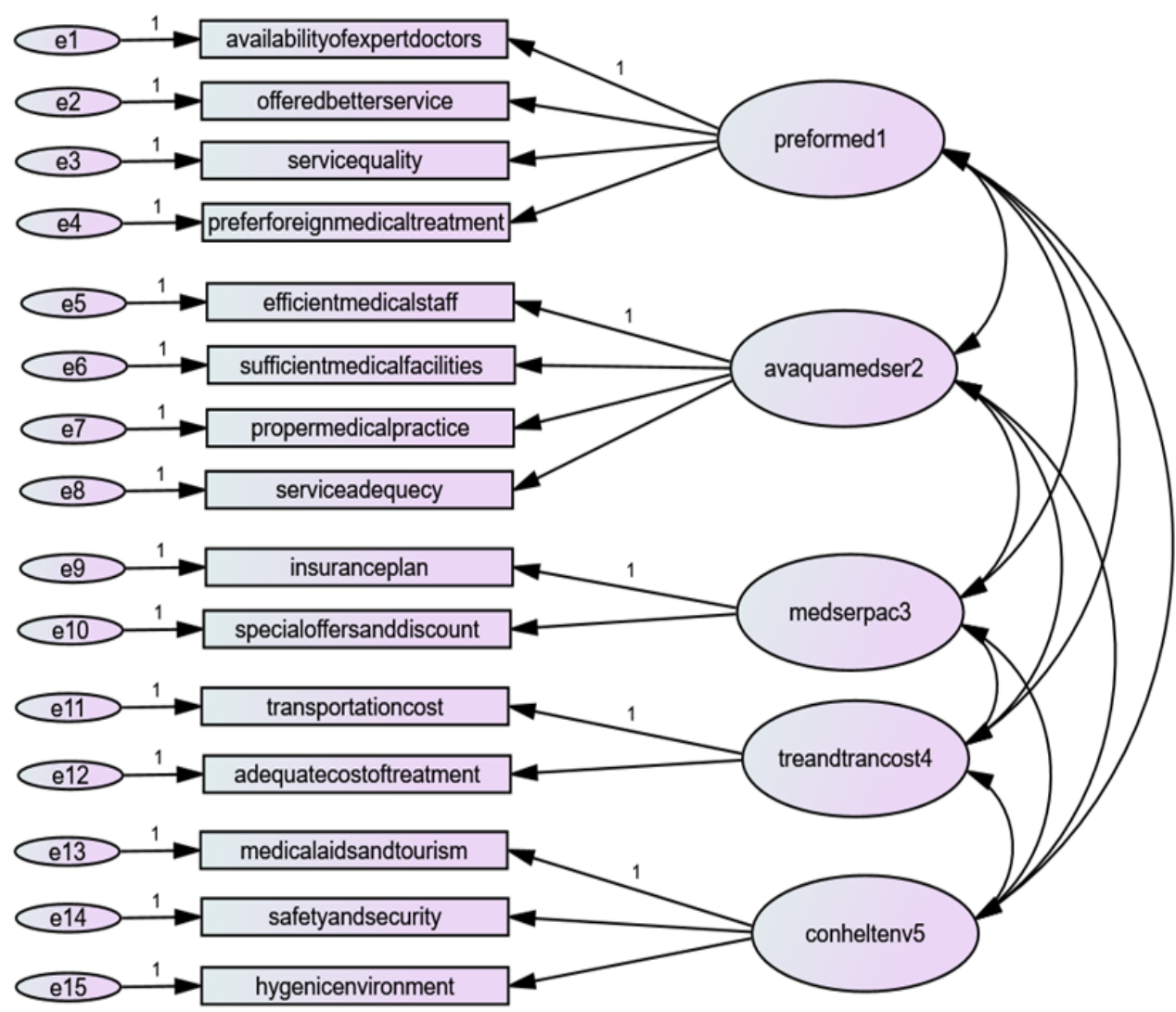

Figure 2: Represent the Confirmatory Factor Analysis Model

Table 4: Represent the Calculated Value of Measurement Fit Index

\begin{tabular}{|l|c|}
\hline \multicolumn{1}{|c|}{ Indicator } & Measures as calculated through AMOS \\
\hline Chi-square $(\boldsymbol{\chi} \mathbf{2})$ & 1.762 \\
\hline p value & .000 \\
\hline Comparative Fit Index (CFI) & .814 \\
\hline Goodness of Fit Index (GFI) & .901 \\
\hline Adjusted GFI (AGFI) & .852 \\
\hline PGFI & .601 \\
\hline Normed Fit Index (NFI) & .716 \\
\hline PNFI & .546 \\
\hline Root Mean Square Residual (RMR) & .059 \\
\hline $\begin{array}{l}\text { Root Mean Square Error of Approximation } \\
\text { (RMSEA) }\end{array}$ & .074 \\
\hline
\end{tabular}

Confirmatory factor analysis has been carried out with the help of a maximum likelihood removal technique. Therefore, data were presented through the measurement model (Figure-2). The model was tested incorporating the quantified association proposed in the hypothesis. The structural model exposes the $\chi^{2}$ value of 1.762 with d.f 105 . The model 
calculated value of RMSEA $=.074, \mathrm{RMR}=.059, \mathrm{NFI}=.716, \mathrm{GFI}=.901, \mathrm{AGFI}=.852$, $\mathrm{PGFI}=.601, \mathrm{PNFI}=.546$, all calculated values are satisfactory.

Hence, the analysis shows that expertise in physician support, service quality, medical service packages, treatment cost, and good health environment are significant, with the P-value is 0.05 . So rejected the null hypothesis and accepted the alternative hypothesis. It's proven that the expertise physician support, service quality, medical service packages, treatment cost, and good health environment significantly influence preferring outbound medical travel.

\section{Discussions and Implications}

The analysis revealed that physician support, service quality, medical service packages, treatment cost, and good health environment have significant affiliation with outbound medical travel (Haque et al., 2018; Kumar \& Raj, 2015). Patients consider better service quality, availability of expert doctors, service quality, sufficient medical facilities, service adequacy, proper medical practice, efficient medical staff, special offers and packages, discounts, insurance plan, transportation and medication costs, hygiene environment, safety and security, medical aids, and tourism attraction sincerely while making their treatment plan (Haque et al., 2018; George, 2009).

According to patients' points of view, above these factors are satisfactory within the country, they make decisions for inbound medical services otherwise they make decisions for better healthcare services and choose outbound medical travel. The current literature of different authors related to medical tourism states that in most of the cases the Bangladeshi patients find themselves dissatisfied with the service quality, availability of skilled doctors, efficient medical staff, costs of treatment, insurance plan, hygienic environment, safety and security that influence them to take the decision for outbound medical travel.

This research has significance for practitioners and authorities of health management. This study's findings provide light on outbound medical travel and the factors that influence them in the context of Bangladeshi patients. It is also useful for practitioners, hospital administrators, and government decision-makers who need to take accurate measures. The healthcare policymaker of Bangladesh may consider the findings and recommendations of this study and develop a year-wise plan to overcome the dissatisfied issues effectively and efficiently, which will certainly discourage people from making a plan for outbound medical travel and will positively impact on the economy of Bangladesh.

\section{Conclusion and Recommendation}

Bangladesh is in a losing position in this sector because many patients and their relatives are going abroad for medical treatment. They received various types of medical treatments like cardiovascular treatments, dental treatments, wellness evaluations, fertility/IVF treatments, cancer treatments, and transplant surgeries from different countries. The majority of the patients like India for their better medical assistance. The main reason for this is India surrounds Bangladesh on three sides. India is an important neighboring country, and its medical services, transportation, accommodation, etc., are relatively more cost-effective than other medical travel destinations. There are some reasons for Bangladeshi patients receiving medical assistance from Singapore, Thailand, Malaysia, etc., because they prefer specialized hospitals, doctors, prime quality medical services, and treatments. 
Finally, the study indicates that the health care services in Bangladesh are not so sufficient for fulfilling the various types of critical treatments and critical patients. So, critical Bangladeshi patients received foreign medical treatment. The study has also found that the patients emphasize some important factors for selecting foreign medical treatments like availability of doctors and better service quality, sufficient medical facilities and services, medical treatment and transportation cost, and hygienic, safety, security, and security attractive tourist medical places. Most of the Bangladeshi patients fully rely on government hospitals. Because the majority of the patients don't have a decent capability to get private hospital service. Some patients, who are wealthy, have a decent capability to buy services from private hospitals in our country and foreign countries.

The Bangladesh government should immediately boost the health sector and develop global standard diagnostic centers, medical colleges, and hospitals. So, the responsible authority should take appropriate policies, actions and guidelines to induce investment by the public-private partnership (PPP) and the private and foreign sectors for developing new diagnostic centers, hospitals, and medical colleges at a world-class level. If policymakers are truly concerned about preventing outflows of cash due to medical care overseas, they must investigate the matter thoroughly. The authority should make genuine efforts at both the government and healthcare professional levels to reduce the number of complaints by enhancing the quality of services provided to patients.

The paper makes many recommendations and opens up a new avenue for long-term researchers to investigate. This study might be developed in the future by collecting additional data from a larger sample size. The sample size was insufficient for extensive study and needed to be increased. Last but not least, this type of study would be fascinating if it was expanded by conducting a larger survey, developing variables, and employing a variety of statistical methods.

\section{References}

Afroz, N., \& Hasanuzzaman, M. (2012). Problems and prospects of tourism in Bangladesh: Bandarban district case, Global Journal of Management and Business Research, 12 (23), 1-9.

Ajmera, P., Satia, H. K., \& Singh, M. (2015). Development of a reliable and valid questionnaire considering indian hospital's perspective of globalization of health in context to India, International Journal of Engineering Research and General Science, 3(1),764-777.

Ali, M. M. (2012). Outbound Medical Tourism : The Case of Bangladesh, World Review of Business Research, 2(4), 50-70.

Ali, M. M.,\& Medhekar, A. (2018). Healthcare Quality of Bangladesh and Outbound Medical Travel to Thailand, Economy of Region, 14(2), 575-588. doi: 10.17059/2018-2-19.

Ali, M. M., \& Medhekar. A. (2016). Globalization, Medical Travel and Healthcare Management in Bangladesh, Problems and Perspectives in Management. doi: 10.21511/ppm.14(2-2).2016.12.

Alom, Z. (2019, July 14). Malaysia woos Bangladeshi medical tourists, The Daily Star, Dhaka,https://www.thedailystar.net/business/news/malaysia-woos-bangladeshimedical-tourists-1771168.

Aniza, I., Aidalina, M., Nirmalini, M. R., Inggit, M. C. H., \& Ajeng, T. E. (2009). Health tourism in Malaysia: The strength and weaknesses, Journal of Community Health, $15(1), 7-15$. 
Aydin, G., \& Karamehmet, B. (2017). Factors affecting health tourism and international healthcare facility choice, International Journal of Pharmaceutical and Healthcare Marketing, 11 (1), 16-36.

Bochaton, A. (2015). Cross-border mobility and social networks: Laotians seeking medical treatment along the Thai border, Social Science \& Medicine, 124, 364-373.

Borg, E. A., Kirsch, F. M., \& Ljungbo, K. (2017). Care, cure and travel towards a symbiosis of medical treatment and tourism? Athens Journal of Tourism, 4(3), 181202.

Chakraborty, S. (2017 April 25). Bangladesh fortifies India's medical tourism sector, Business Standard, New Delhi, India, https://www.business-standard.com

Collins, A., Medhekar, A., Wong, H. Y., \& Cobanoglu, C. (2019). Factors Influencing Outbound Medical Travel from the USA, Tourism Review, 74(3):463-479. doi: 10.1108/TR-06-2018-0083.

Deloitte. (2011). Medical tourism in Australia: a scoping study, department of resources, Energy and Tourism, Retrieved: 10 August 2014, from http://www.deloitte.com

DGHS. (2020). Health Bulletin, Health Division, Dhaka, Bangladesh, 2019.

Elflein, J. (2020). Diseases, Statistics \& Facts, Statista. Retrieved (https://www.statista.com/topics/2070/diseases/).

ETA. (2012). Health Care Initiatives. Employment and Training Administration, United States Department of Labor. Retrieved (https://web.archive.org/web/20120129005204/http://www.doleta.gov/BRG/Indpro $\mathrm{f} /$ Health.cfm).

George, B. (2009). Medical tourism in India: A case study of Apollo hospitals, in Smith, M. and Puczko, L. (Eds), Medical and Wellness Tourism, Elsevier Science and Technology Books, Burlington, MA, pp. 367-72.

Haque, A., Yasmin, F., \& Anwar, N. (2018). Factors determinant of patients' satisfaction towards health tourism in Malaysia, International Tourism and Hospitality Journal, 1 (1), 1-18.

Hasan, S. R., \& Hassan, K. (2013). Health Tourism: A Demographic Study on the Outbound Health Tourists from Bangladesh. Journal of Business, 34(2).

Horowitz, M. D., Jeffrey A. R., \& Christopher A. J. (2007). Medical Tourism: Globalization of the Healthcare Marketplace, Medscape General Medicine, 9(4).

Islam, A., \& Biswas, T. (2014). Health System in Bangladesh: Challenges and Opportunities, American Journal of Health Research, 2(6):366. doi: 10.11648/j.ajhr.20140206.18.

KFF. (2006). Snapshots: Comparing Projected Growth in Health Care Expenditures and the Economy. Retrieved (https://www.kff.org/health-costs/issue-brief/snapshotscomparing-projected-growth-in-health-care-expenditures-and-the-economy/).

Khaled, S. M. S. (2017, May 17). Bangladesh Yet to Make a Breakthrough in the Health Sector, The Daily Independent, Dhaka, http://m.theindependentbd.com.

Kumar, D., Haque, A., \& Dhar, P. (2021). Exploring the Critical Influencing Factors of Customer Satisfaction in Telecommunication Sector in Bangladesh, Asia-Pacific Journal of Management and Technology, 1(4)11-21,

Kumar, G. S., \& Raj, R. K. (2015). Status, growth and impact of medical tourism in India, Int. J. Pharm. Sci. Rev. Res., 34 (1), 284-291.

Kunwar, R., \& Srivastava, V. K. (2019). Operational research in healthcare settings. Indian J Community Med [serial online] 2019 [cited 2021 May 22]; 44: 295-8. Available from: https://www.ijcm.org.in/text.asp?2019/44/4/295/270812 
Lajevardi, M. (2016). A comprehensive perspective on medical tourism context and create a conceptual framework, Journal of Tourism, Hospitality and Sports, 20, 7-25.

Leng, C. H. (2007). Medical tourism in Malaysia: international movement of healthcare consumers and commodification of healthcare (Working Paper Series83). Singapore, Singapore: Asia Research Institute. Retrieved from https://papers.ssrn.com/sol3/papers.cfm?abstract_id=1317163Mehrens, W.A., \& Lehmann, I.J. (1987). Using standardized tests in education. New York.

Mahmood, S. A. I. (2012). Health Systems in Bangladesh, Health Systems and Policy Research, 1(1), 1-4. doi: 10.3823/1100.

Maswood, M. H. (2017 September 17). Patients flock abroad lack of confidence in doctors, political commitment to improving facilities, doctors' behavioral problems, The Daily New Age Bangladesh, Dhaka, http://www.newagebd.net

Maung, N. L. Y. M., \& Walsh, J. (2014). Decision factors in medical tourism: evidence from burmese visitors to a hospital in Bangkok, Journal of Economics and Behavioral Studies, 6 (2), 84-94.

McKinsey. (2008).Quarterly, Mapping the Market for Medical Travel, p. 2.

Medical Tourism Magazine. (2019). Compare and Contrast Inbound vs. Outbound Healthcare, MedicalTourism.Com. Retrieved (https://www.magazine.medicaltourism.com/article/compare-and-contrast-inboundvs-outbound-healthcare).

Mestrovic, T. (2021). News Medical Life Science, World Medical Tourism Review, Retrieved (https://www.news-medical.net/health/World-Medical-TourismReview.aspx).

Mokoena, L. G., \& Haarhoff, R. (2016). Medical tourism: investigating the tourism potential of the medical cosmetic market, African Journal of Hospitality, Tourism and Leisure, 5(4), 1-16.

Musa, G., Thirumoorthi, T., \& Doshi, D. (2012). Travel behaviour among inbound medical tourists in Kuala Lumpur, Current Issues in Tourism, 15(6), 525-543.

Rahman, M. (2000). Bangladesh-India Bilateral Trade: an Investigation into Trade in Services. South Asia Network Economic Research Institute (SANEI) Report, Dhaka.

Rahman, M. (2019, June 27). Medical tourism et al, it is a trend that looks to be thriving in the region, Dhaka Tribune, Dhaka, https://www.dhakatribune.com

Special Correspondent. (2018, May 30)700,000 Bangladeshis go abroad for health services every year, The Apparel News, http://theapparelnews.com/article/1731/index.html.

Sun, X. (2018). Research on the model of cross-border medical tourism decision-making under the background of globalization. Open Journal of Social Sciences, 6, 230246. doi: $10.4236 /$ jss.2018.69016.

Tontus, H. O., \& Nebioglu, S. (2018). Drivers of healthcare globalization and their effects on medical tourism, e-Review of Tourism Research (eRTR), 15(2-3), 255-272.

Zahid, S. H. (2019, October 20) High cost of treatment abroad, The Financial express, https://thefinancialexpress.com.bd/views/high-cost-of-treatment-abroad1571587310

Zaidi., Anita K. M., Awasthi, S., \& DeSilva, H. J. (2015). Burden of Infectious Diseases, Clinical Review, 50(11). 